\title{
A correlation between pavement skid resistance and wet- pavement related accidents in Thailand.
}

\author{
Jumrus Pitaksringkarn ${ }^{1,}$, Ladda Tanwanichkul ${ }^{2}$, Kwanruen Yamthale ${ }^{2}$ \\ ${ }^{1}$ Civil Engineering Department, Faculty of Engineering, King Mongkut's Institute of Technology Ladkrabang, Bangkok, Thailand \\ ${ }^{2}$ Civil Engineering Department, Faculty of Engineering, Khon Kaen University, Thailand
}

\begin{abstract}
This research aims to study a correlation between a pavement skid resistance and wet-pavement related accidents in order to determine the minimum friction threshold so called 'Investigatory Level (IL)' for the roads in Thailand. An accident database, a skid resistance database and a traffic volume of road network from the department of Highways, totalling 19 routes and 386kilometers, were used in the analysis of this study. In the analysis, 500-meter subsection intervals are used to determine a correlation between an average pavement skid resistance and wet-pavement accident rate using a non-linear regression analysis model. It was discovered that the pavement skid resistance has a major influence on the accident rate, depending on various types of road geometry. Moreover, the preliminary investigatory level is determined by using a past accident rate information as a reference for an investigatory level basis. We discover that the single carriageway (non-event) road is at highest threat due to low pavement skid resistance. The recommended investigatory level for each of the five road geometries all site, single carriageway, dual carriageway, horizontal alignment and curve road categories are $035,0.50,0.30,0.30$, and 0.40 , respectively, which are in accordance to the investigatory level values in other countries.
\end{abstract}

\section{Introduction}

Three key elements of accident causes are road users, vehicles and road environments which could be one or a combination of those elements. From Department of Highway report, it was shown that 3 major causes of accident in the network including speeding, short cut-off driving and illegal overtaking [1]. The single vehicle accident as the type of run-off road crash is mostly caused by speeding on a low pavement skid resistance road. As a result, vehicle speeding is a potential factor in causing road accident especially on low friction pavement which could increase road crash numbers on the road network [2]. In fact, friction surface or skid resistance of road pavement could be one of the accident causing factors. This is because at the same level of speeding, the vehicle requires longer distance to stop on the road with low friction. The skid resistance of an asphalt pavement is of critical importance because it directly relates to the safety of motorists and their ability to stay on the road and be able to stop effectively. Skid resistance can be affected by several factors including the environment, roadway surface characteristics, and roadway geometry.

A correlation between traffic accidents and pavement surface characteristics has been researched and examined in many studies. In the study of [3], the number of wetpavement skid crashes increases as the skid friction value decreases. Other studies focus on wet-pavement accidents by observing pavement skid resistance of road surface in different road geometries, such as single/dual carriageway, bending curve, and intersection area. Road pavements provide two main services including a functional service and a structural service. One of the important factors that determine a pavement functional service is the level of skid resistance due to the fact that safe driving depends on an adequate surface friction for vehicle manoeuvring, turning and braking. Skid resistance is therefore considered as one of the most important surface characteristics as it has a direct impact on traffic safety [4].

Therefore, the role of skid resistance standard in reducing accidents together with the role of surface texture as major factors in accident reduction is currently under reviewed by a number of highways agencies. Various studies employed using a relationship between accident rates and skid resistance in different road types and road geometries in order to establish an investigatory level of skid resistance [5-6]. This research thus aims to determine a correlation between wet-pavement accident rates and pavement skid resistance in order to initially establish the investigatory level of skid resistance for National Highway in Thailand adopted from the Department of Highway (DOH).

\section{Road accident and skid resistance}

Wet pavement accidents and a total number of accidents were used to study the relationships between

* Corresponding author: jumrus@gmail.com 
pavement skid resistance and a total number of wet pavement accidents on major highways in the Kingdom of Saudi Arabia [7]. It was concluded that the number of accidents approaches almost a constant number at a skid number greater than 0.45 . Moreover, the correlation between total traffic accident rates and the skid number (SN) was found to be statistically significant with high accident rates within and outside the capital city, Amman. The statistically significant negative correlation indicates that skid resistance is an important contributing factor in traffic accidents causation. This agrees with the findings of other research works stating that lower levels of Skid Number (SN) are likely to lead to a higher potential traffic accidents and also to a higher rate of fatal accidents [8].

The skid resistance offered by a wet road surface decreases with increasing travel speeds [9].This indicates that wet surface is likely to affect on the number of accidents, especially in speeding vehicles. [10] studied a relationship between skid resistance and wet pavement accidents on local roads in the Southwest of England aiming to determine the safe skid resistance threshold (according to IL HD28/04 standard) for local roads. And the results in both individual local counties and combined one showed strong relationships between wet accident rate and skid resistance which is similar to the study by [3, 11-12].

Road geometry type is the other factor that is usually concerned in an analysis of skid resistance and traffic accidents. In the studies by $[2,13]$, both linear and nonlinear correlation between skid resistance and accident indicating different road geometries especially sharp curves which affect skid resistance, resulting in a higher number of wet pavement accidents comparing to other types of road geometries. [2] provides an overview of the four locations the skid resistant material was placed and their respective performance and wear characteristics over one winter and after two years.

This research will explore and determine relationship between wet pavement accident rates and pavement skid resistance in order to estimate an Investigatory Level (IL) for Asphalt Surface Road considering in different accident locations and road types. Thus, relationship between wet accident and skid resistance will be determined as well as divided into different road types in order to preliminarily establish investigatory level for DOH network in Thailand.

\section{Research methodology}

\subsection{Data collection and analysis}

Skid resistance data, accident data, and traffic data are used for establishing skid resistance and traffic accident relationship in order to determine preliminary result of threshold investigatory level.

Accident and skid resistance databases during the year of 2011 to 2012 were acquired from the Department of Highway (DOH). Wet pavement accident locations and skid resistance data are encoded into a GIS map. Then the overlays of both layers, i.e. data wet accident and skid resistance data in the GIS map are used to count accident frequency and calculate an average friction of the 500-meter subsection interval of road section. Accordingly, 19 routes with the total distance of 386 kilometres covering 9 provinces in 9,000 kilometres in Thailand were selected for analysis in this study as shown in Figure 1. Skid resistance and accident data associated traffic volume and other data will be used to calculated following to selected study area.

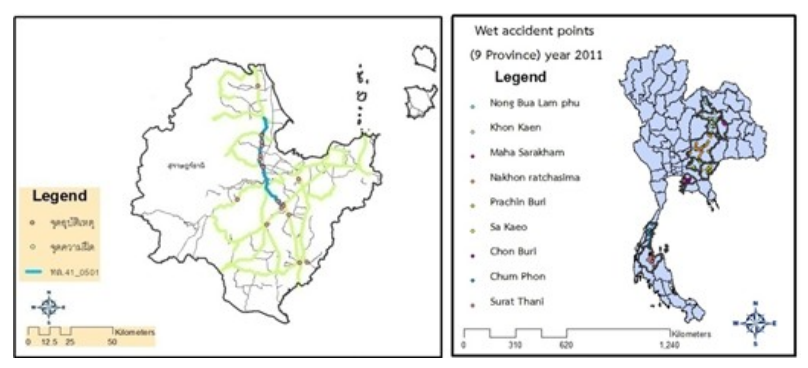

Fig. 1. Overlaid maps of skid resistance and wet accident location and selected wet accident Locations

\subsection{Investigatory levels}

The investigation level (IL) is a skid resistance maintenance priority level that has been set with the objective of equalizing the personal risk (crash rate rather than crash number) of a wet road skidding crash across the state highway network, while maintaining an economic balance between the cost of achieving the skid resistance and the crash savings [14], p 4. Moreover, investigatory levels for skid resistance are generally used as maintenance strategies in many road agencies [15]. It is therefore required to understand the measuring device outputs with respect to intuitive investigatory levels will need to be a prerequisite to such exercises. Many countries for example United Kingdom, Australia, and New Zealand consider to monitoring skid resistance level of pavement of road network [3]. In fact, along a highway with different geometry of the elements (gradient, bend radius), environmental conditions and circumstances, the threshold between 'safe' and 'potentially unsafe' are difficult defined by a unique level of skid resistance. Therefore, a set of skid resistance levels are considered for different situations and conditions. 
Table 1. Minimum Skid Resistance Threshold in different countries

\begin{tabular}{|c|c|c|}
\hline Country & \multicolumn{2}{|c|}{ Minimum Skid Resistance Threshold } \\
\hline \multirow{6}{*}{$\begin{array}{c}\text { United } \\
\text { Kingdom } \\
\text { (HD 28/04) }\end{array}$} & Motorway & 0.35 \\
\hline & Dual Carriageway non event & 0.35 \\
\hline & Single Carriageway non even & 0.40 \\
\hline & Dual Carriageway (All purposes) & 0.40 \\
\hline & Bend - Dual carriageway & 0.45 \\
\hline & Bend - Single carriageway & 0.50 \\
\hline \multirow{9}{*}{$\begin{array}{c}\text { Australia } \\
\text { (Long, Wu } \\
\text { et al. 2013) }\end{array}$} & Intersection with controls & 0.55 \\
\hline & Curves with tight radius & 0.50 \\
\hline & Intersections & 0.45 \\
\hline & Free areas of Undivided roads & 0.40 \\
\hline & Free areas of Divided road & 0.35 \\
\hline & Road Junction Approaches & 0.35 \\
\hline & Curve $<250 \mathrm{~m}$ & 0.40 \\
\hline & $\begin{array}{l}\text { Undivided Carriageway (non- } \\
\text { event) }\end{array}$ & 0.35 \\
\hline & Divided Carriageway (non-event) & 0.25 \\
\hline
\end{tabular}

\subsection{Road category: accident and skid resistance models}

Roadway geometry is one of important factors affecting skid resistance of road surface which is related to road accident [2] since skid resistance directly related to the ability of motorist to control the vehicle to be able to stop effectively. Moreover, in a larger-scale study of the link between skid resistance and personal injury accidents, based on $1,000 \mathrm{~km}$ of road network [16], it has been confirmed that the different levels of accident risk for different types of road site and the increase in risk for sites with lower skid resistance. As a result, in this research, types of road geometry will be considered for using in categorize relationship between wet accident rate and skid resistance. The set of category will be also used for establishing the investigatory levels of minimum skid resistance number of road pavement surface. By different types of road geometry, there five models will be categorized using for analysis relationship between skid resistance and road accident in the research as details following:

Table 2. Model Road Types

\begin{tabular}{|l|l|}
\hline Model & Description \\
\hline M1 & All site - Accident on two or more -lane roads \\
\hline M21 & Single carriageway - Accident on two-lane roads \\
\hline M22 & $\begin{array}{l}\text { Dual carriageway - Accident on more than two-lane } \\
\text { roads }\end{array}$ \\
\hline M31 & $\begin{array}{l}\text { Horizontal Alignment - Accidents on all types of } \\
\text { road }\end{array}$ \\
\hline M32 & Curve - Accident on two or more -lane roads \\
\hline
\end{tabular}

\section{Analysis results}

Non-linear regression analysis was used to establish relationship between skid resistance and wet accident for all five types of road geometry. Correlation coefficient, value of $\mathrm{R}^{2}$ represents the friction of the road influence the accident rate whereas testing of the F-Test of the model indicates level of the road friction influencing the accident rate which is more than 95. In fact, the single carriageway and curve trends have higher decreasing trend comparing to the trends of dual carriageway and horizontal. In the conclusion, single carriageways and curve roadways are higher risk to wet accidents comparing with dual carriageways and horizontal roadways in term of skid resistance of roadway. Figure 4 to 6 present relationships and trends of 5 models of relationship between skid resistance and road friction.

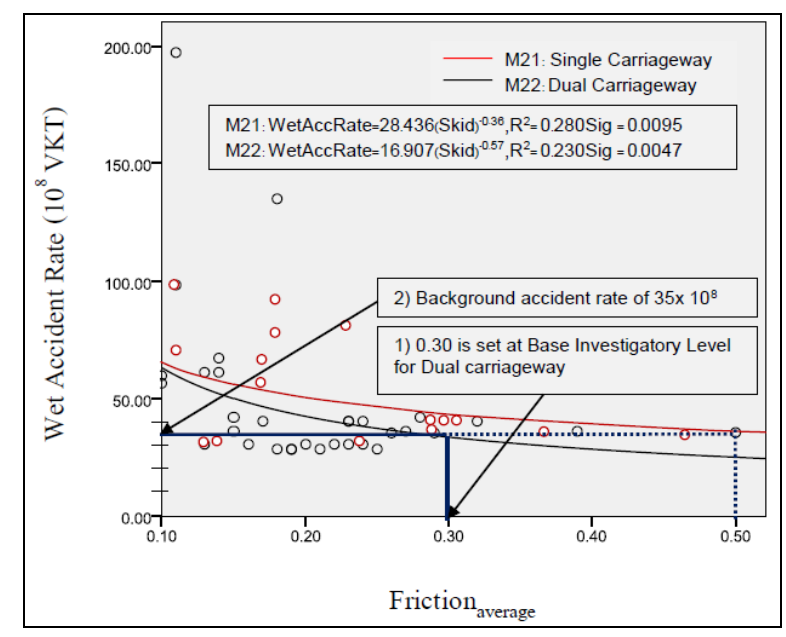

Fig. 5. M21-Single carriageway and M22-Dual carriageway non-events

Guideline from [17] to determining investigatory level is summarized from a work example in a guideline study. A 'base investigatory level' of different site categories will be set and then it will be used to determine an investigatory level for the other categories. Therefore, 4 steps taken from Austroads work will be used to determine IL for different site categories of road geometry in this research:

1. Establish trend of relationship between wet accident rate and skid resistance: Trends of relationship between wet accident rate and skid resistance for 5 categories.

2. Get the base investigatory level from existing guideline in different site categories: guidelines of investigatory level from United Kingdom, Australia, and New Zealand are summarised in Table 3. Base investigatory level is set at 0.30 for dual carriageway based on values from UK, Australia, and New Zealand at $0.35,0.35$ and 0.25 respectively.

3. Select a background accident rate for using in comparison of crash risk across different risk categories: in this research, wet accident rate from a low risk road category i.e. dual carriageway type will be used as back ground accident rate of 35 (108 VKT) for base investigatory level at 0.30 .

4. Set investigatory level for each category: At 35 of wet accident rates, investigatory level for five categories can be set as detail in Table 4.The wet accident rate 
slightly decreases or remains steady when average friction increase therefore investigatory level (IL) can be approximately established. The friction increments 0.05 are used for consideration in the trend shown in previous section. Summary of preliminary investigatory level (IL) for five categories are M1, M21, M22, M31, and M33 are $0.35,0.50,0.30,0.30$, and 0.40 respectively.

\section{Conclusion and discussion}

The relationships between wet accident rates and skid resistance of Highway Road in Thailand were examined for five models including all site, Single carriageway non-event, Dual carriageway non-event, Horizontal Alignment and Curve. It was found that wet accident rate is inversely proportional to skid resistance for all categories. As a result, wet accident rate decreased as and skid resistance increased. By using method recommended in a guideline from Austroads, dual carriageway road type was selected as the base investigatory as 0.3 and resulting of a background accident rate at 35 (108 VKT). As a result, preliminary investigatory Level (IL) can then be determined for three categories of five sub-models including All Site, Single carriageway non-event, Dual carriageway non-event, alignment and Bend for 0.35, 0.50, 0.30, 0.30 and 0.40 respectively. It was found that ILs from this study corresponding to ILs from other study such as study of $[6,10]$. As a result, the preliminary investigatory level can be used as support tool in making decision for maintenance schedule of road surface monitory. Preliminary ILs could then be used as verify-tool to be more precise for road maintenance schedule for the road surface friction of Thailand. As a result, appropriate skid resistance would be maintained and wet accident could then be reduced.

\section{References}

1. Bureau of Highway Safety. Bangkok, Department of Highway, Ministry of Transport, Thailand. (2013)

2. M. Karim, J. Chyc-Cies, et al. Conference of the Transportation Association of Canada Fredericton. New Brunswick, Canada: 1-10. (2012)

3. B. Crisman and R. Roberti. Procedia - Social and Behavioral Science 53: 1055-1068. (2012)

4. N. Piyatrapoomi, J. Weligamage, et al. Proceedings of the International Conference on Managing Road and Runway Surfaces to Improve Safety, Cheltenham, England. (2008)

5. J. Kudrna, A. Vojtelek, et al. Road Skid Resistance Influence on the Number of Crash Accidents. (2007)

6. A. Stevenson and M. Phillips. International Safer Roads Conference, May 2008. (2008)

7. A. I. Al-Mansour. The Journal of Engineering Research 3(1): 75-78. (2006)

8. K. Ramadan and I. M. Muslih. Jordan Journal of Applied Science 'Natural Sciences Series' 11(1): 11 18. (2013)
9. Road Safety Observatory. Synthesis title: Surfaces, Observatory main category: Roads. Retrieved 26 September 2015, from http://www.roadsafetyobservatory.com/Review/100 $\underline{51}$.

10. Kennedy, C. and J. Donbavan. International Safer Roads Conference 2008. (2008)

11. J. S. Kuttsech. Master of Science In Civil and Environmental Engineering: Blacksburg, Virginia, Virginia Polytechnic Institute and State University. 147. (2004)

12. H. E. Viner, R. Sinhal, et al. Linking Road Traffic Accidents With Skid Resistance - Recent. UK Developments. 1-13. (2005)

13. M. Saplioglu, E. Eriskin, et al. $10^{\text {th }}$ International Congresson Advances in Civil Engineering. Ankara, Turkey: 1-10. (2012)

14. W. Kotahi. Notes to specification for state highway skid resistance managment. NZ Transport Agency: 20. (2012)

15. C. Blanchard and D. Hollaway. Road Surface Friction (Skid Resistance \& Pavement Texture): Recommended Investigatory Levels. Department of Planning, Transport and Infrastructure: 4. Adelaide. (2003)

16. M. P. Rogers and T. A. Gargett. Highways and Transportation, 38, 10-16. (1991)

17. Austroads. Development of Safety Related Investigatory Level Guidelines: A Worked Example of Methodology. Sydney, Department of Planning, Infrastructure and Transport SA: 17. (2013) 